The Territorial Imperative, by Robert Ardrey. Collins, 36s.

Robert Ardrey is a playwright who has confidently ventured into biology. He believes that much of human conflict can be attributed to man's territorial behaviour and that this supposed trait can be better understood by comparing it with similar behaviour in other animals. It is a view which is at least worth considering. However, the arguments on which he bases his conclusions are shot through with such elementary mistakes, and his definitions are so loose, that he will surely mislead anyone who takes him seriously. Take, for example, his inability to distinguish process and function. He sees territory not as a result of behaviour but as a mechanism which is basically similar in all territorial animals. He discerns the evolutionary beginnings of this process in slime moulds and traces it through a heterogeneous collection of species up to man. The near certainty that territorial defence has evolved at different times and for different reasons never seems to occur to him.

Ardrey is at his best when he is merely reporting. Some of his descriptions of behaviour are marvellously vivid and exciting. I suspect that his qualities as a writer are just those which make him so poor as a thinker. For the sake of a good story, complex issues are reduced to glib alternatives; either structure affects the evolution of behaviour or the other way about; either behaviour patterns are learned or they are inherited. This makes for good journalism but bad science. Indeed, Ardrey seems to be scarcely aware of the interactions involved in biological processes and to know nothing of scientific method, which probably accounts for the worthless theorising at the end of the book. All of this is a pity because some of the issues which he raises are important. Before the face of the world changes too much, it is essential that the requirements of threatened animals are understood. In many species, including man, it may be necessary to take account, among other things, of territorial behaviour. However, the need to do so has yet to be established.

P. P. G. BATESON

\title{
The Penguin Dictionary of British Natural History, by Richard and Maisie Fitter, $8 \mathrm{~s} .6 \mathrm{~d}$.
}

Richard Fitter is the Hon. Secretary of the Fauna Preservation Society, Maisie Fitter edits ORYX, and together they have written this dictionary. Consequently the reviewing of their book for this journal must be puritanically objective, and one must reflect upon their joint endeavour with the unfeeling obduracy of a plate glass mirror. To be objective in this sense means determinedly describing all the warts, every blemish.

The trouble is I personally relish works of reference. To me the money spent on an atlas or a dictionary, for example, is incalculably well spent. And works of reference that are cheap will surely repay any modest outlay before they crumble to their premature paperback deaths. Apart from these merits this particular book by the Fitters has much else to commend it. The style is often pleasing ("beetles familiar for their bumbling flight at dusk") and there are delightful extras to the ordinary definitions ("The plant popularly known as the bulrush, thanks to the Victorian painting of Moses in the bulrushes, is actually the great reed-mace Typha"). Many dictionaries are totally unhuman, in that they are written soullessly like the instructions with card-games and car manuals. Being more human the Fitter dictionary is more likely to be imprecise - "whose larvae feed on carrion and other decaying animal matter," an eyrie "is usually placed on a more or less inaccessible rock ledge." Would not pedants say that carrion is decaying animal matter, and eyries are quite accessible to eagles. Why, I wonder, is dextral "Of snails coiling right-handed" when sinistral is "Spiralling left-handed, especially of snail shells"? 
The book is also human in that it takes a liberal view of natural history, including definitions of fat-basket, harvest moon, World Wildlife Fund, pH, nature trail, conker. It gives slangy terms, and words only used in certain parts of the country, like Easter-Ledge (Lake District for bistort), Rail (Irish for caddis flies), Corbie (Scottish for raven), Heathpoult (Somerset for black grouse), Ouzel (Old English for blackbird). It is good to find that the definition of rabbit is enlarged with a short description of myxomatosis, that so many alternative names are given, that there is an index of species at the back of the book, and that 348 pages of fact can be bought for $8 \mathrm{~s}$. $6 \mathrm{~d}$. In short, I welcome and applaud this Fitter dictionary, and I hope its paperback format manages to survive the inevitably frequent investigations into its contents.

ANTHONY SMITH

Dawn, Dusk and Deer, by Arthur Cadman. Country Life, 30s.

Arthur Cadman has set himself the task of instructing the beginner in the art, science, intricacy and fascination of watching, studying and managing deer. He has salted his many lessons in venery with a number of homely, delightful and often amusing experiences.

Those who know the author personally will appreciate the forthright and often boyish enthusiasm that reveals his character in every line. For he is one of those nowadays rare people who live for as well as in the countryside, and for whom the changing faces of both animal and plant life, the variations of the weather, all add zest to his being.

Good wine tastes better out of beautiful glass and every book has added charm if attractively presented. Country Life and Mr. Tunnicliffe have played their part to ensure that this book shall appear to the best advantage. As always, Tunnicliffe has managed to portray the animals at their most graceful and appealing, and once again dumbfounds those who find animal pictures banal. His black and white drawings are lavishly spaced through the book and this alone makes it a must for one's library shelf. But such a book demands a second volume to satisfy the appetite it has produced.

DUDLEY FORWOOD

\section{Birds in our Lives, edited by Alfred Stefferud: US Department of} the Interior, $\$ 9.00$

The aim of this American book as stated by the editor is to widen public understanding of birds by giving a broad perspective of them as they affect and are affected by people, other birds and other forms of life and activities. He believes that this is the best way to achieve public support. His book should do just this. It is one of the most wide-ranging, popular symposiums on the subject of birds for the ordinary bird-watcher and bird lover in existence, imposing not only for its subject matter, which naturally chiefly concerns American birds, but also for the range of authors, beginning with a foreword by Stewart Udall, Secretary of the Department of the Interior, who emphasises that in this technological age there is necessity for us to learn about the inter-relationships of all living things.

All aspects of birds are treated, beginning with a look at the birds themselves and what they are, what they mean to us, their place in the arts, in recreation, as an economic problem, in nature, and finally their conservation and protection. Although each of the fifty-four chapters within the sections is comparatively short, the depth of treatment is impressive and often gives a comprehensive summary of the particular subject. Illustrations include 372 black and white photographs, mostly of very high standard, and 80 wash drawings by Bob Hines.

PETER CONDER 